\title{
O OBJETO MEDIADOR NA LITERATURA FANTÁSTICA
}

Rhuan Felipe Scomação da Silva ${ }^{1}$

RESUMO: Este trabalho tem como objetivo estudar a aparição e o efeito do objeto mediador na narrativa fantástica, assim como categorizar três possíveis formas de utilização desta ferramenta na obra literária. A partir da proposta de Ceserani sobre o objeto mediador, onde o crítico o classifica como o atesto de uma verdade inequívoca porque inexplicável e inacreditável dentro da narrativa, o artigo procura evidenciar estas aparições nas obras como um mecanismo de conexão entre a realidade e a ficção. As três maneiras como elencamos a forma de aparição deste mecanismo (o objeto físico inanimado, a entidade sobrenatural física e a invocaçãolevocação de um ser sobrenatural invisível) são estudadas a partir de exemplos, pontuando suas presenças e suas influências na trama narrativa. Com isso, propõe-se estudar um mecanismo narrativo que evidencia a presença do sobrenatural e coloca a narrativa fantástica para além da hesitação. A aparição do objeto mediador estará geralmente conectada com a presença inquestionável do sobrenatural, por isso torna-se tão poderosa como ferramenta e tão importante na sua atividade de mediação entre o real e o fantástico.

PALAVRAS-CHAVE: Objeto Mediador; Fantástico; Sobrenatural

\section{INTRODUÇÃO}

Nas últimas quatro décadas, o estudo que leva em consideração a atuação e o efeito da literatura fantástica no público leitor e na história da literatura em si tem recebido uma grandiosa contribuição de diversos críticos, pensadores e pesquisadores ao redor do mundo, como o singular trabalho de Tzetan Todorov com Introdução à Literatura Fantástica (2014), onde o pesquisador expõe a ideia do fantástico como gênero literário a partir de sua conhecida tríade Fantástico-Maravilho-Estranho. Além disso, inclui teóricos como Caillois e sua ideia de que o fantástico sobrenatural aparece como uma ruptura da coerência universal, "O prodigioso se mostra, aqui, como uma agressão proibida, ameaçadora, que rompe a estabilidade de um mundo no qual as leis haviam sido consideradas, até então, como rigorosas e imutáveis" (CAILLOIS, 1966, p.11), e Bessiere (2009) quando comenta sobre a questão de representação entre o real e o irreal exposto pelo fantástico. Podemos citar também críticos mais contemporâneos como David Roas e sua proposta do fantástico como caracterização de um conflito entre a ideia do real e do impossível, ou a visão de Rabkin (1977) quando propõe um espanto do leitor ao perceber a inversão em 180 graus da realidade empírica da narrativa em direção ao fantástico.

\footnotetext{
${ }^{1}$ Mestre em Linguagem, Identidade e Subjetividade pela Universidade Estadual de Ponta Grossa, UEPG. Email:rfss_hcp@hotmail.com
}

Revista de Letras JUÇARA, Caxias - Maranhão, v. 02, n. 01, p. 263 - 277, jul. 2018 | 263 
Expostas estas ideias e pensando no impacto que elas vêm causando na crítica de textos com o viés fantástico, este trabalho tem como indicativo central estudar o Objeto Mediador. Esta proposta foi inicialmente apresentada por Remo Ceserani em seu livro O Fantástico (2006), e considera, a partir da interferência de um objeto, entidade ou qualquer outro artifício da narrativa, uma mudança de plano, realidade ou inferência de algo sobrenatural que vai alavancar a narrativa a partir desta ruptura com a realidade empírica do leitor.

Para expor melhor a ideia do objeto mediador, vejamos a fala do próprio Ceserani acerca da ferramenta.

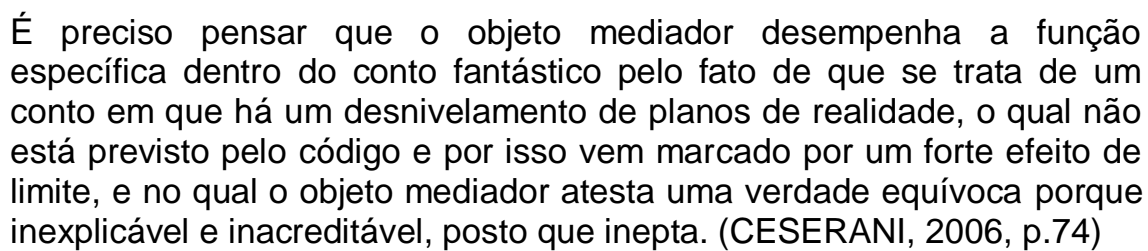

Nela, o crítico expõe a ideia de que este objeto (no caráter simbólico da palavra) irá causar o estranhamento dos personagens, que até aquele momento acreditavam conhecer a realidade, e com isso ajudar a construir um pacto ficcional onde o leitor se tornará capaz de questionar o real narrativo frente à súbita projeção do fantástico no enredo.

Para tanto, encontramos três formas recorrentes da aparição deste objeto mediador nas narrativas, as elencamos em grupos de efeito e trazemos alguns exemplos que ilustram sua presença e importância nas narrativas que serão destacadas em seguida.

\section{AS TRÊS FORMAS DE APARIÇÃO}

Antes de iniciarmos a exposição, vale lembrar que estas não são as únicas formas de apresentação do objeto mediador na literatura fantástica, mas sim aquelas encontradas em maior número durante as leituras. Trazemo-las com o intuito de construir um cabedal de referência, não de regra.

Dividimos a forma da aparição do objeto mediador em três níveis. O primeiro tem relação com um objeto físico, seja ele caracterizado como místico, tecnológico ou mágico. O segundo tem relação com a aparição de uma entidade, seja ela um fantasma, um alienígena, um viajante no tempo ou qualquer outro ser 
cósmico. E o terceiro tem relação com a ativação de algo a partir de um gatilho aqui, encaixam-se os encantamentos, as palavras de poder e orações, desde que não haja uma interseção visual destas ativações na percepção inicial do fantástico.

No primeiro nível encontram-se o maior número de exemplos da aparição do objeto mediador. Escolhemos duas narrativas para representar esta aparição: a primeira é uma ferramenta estética do escritor estadunidense Howard Phillips Lovecraft, intitulada Necronomicon. Nela, encontramos o objeto mediador como místico-tecnológico.

Já no segundo exemplo encontramos o objeto mediador como mágicomitológico a partir da narrativa Aladim e a Lâmpada Maravilhosa, dos contos de Sherazade da coletânea das Mil e Uma Noites.

Lovecraft constrói no decorrer de suas narrativas uma mitologia acerca do Necronomicon, um livro contendo o conhecimento capaz de invocar criaturas de outros planos de existência, descobrir segredos guardados por milênios e ter acesso a ensinamentos que desafiariam qualquer ciência humana.

A aparição do livro em seus contos é repleta de um horror cósmico e de uma aversão por parte dos personagens ao livro amaldiçoado, como em Nas Montanhas da Loucura no primeiro exemplo e como em O Horror de Dunwich no exemplo seguinte:

Naquele momento, arrependi-me de ter lido o execrando Necronomicon e conversado tanto com Wilmarth, o desconcertante folclorista erudito da universidade. (LOVECRAFT, 2013, p.574)

Mas naquele instante teve a impressão de sentir a presença imediata de uma parte terrível desse horror insidioso e de vislumbrar um movimento demoníaco nos domínios do pesadelo ancestral e outrora inerte. Trancou - Necronomicon com um calafrio de desgosto, mas na biblioteca ainda pairava um fedor blasfemo e ignoto. (LOVECRAFT, 2013, p.387)

Ambas as aparições possuem uma intenção direta de causar o questionamento, o abalo realista na construção do universo ficcional em relação à verdade empírica previamente carregada pelo leitor modelo. O Necronomicon é um objeto capaz de transpassar a realidade e atingir um espaço desconhecido e fantástico onde os personagens se arrependem de ter entrado em contato.

A reação regular dos personagens da obra lovecraftiana em contato com o objeto mediador é o afastamento e a negação, mas, em algumas oportunidades, 
esta reação é seguida por um questionamento e uma curiosidade do que está do outro lado. Em Um Sussuro nas Trevas, quando o protagonista encontra uma máquina capaz de conversar com criaturas espaço-temporais adversas a seu conhecimento, reconhece inúmeras possibilidades de descoberta e aceita 0 objeto como algo benéfico à sua curiosidade, explicando e maravilhando-se com a tecnologia.

Era possível extrair um cérebro sem nenhum prejuízo ao hospedeiro e manter os resíduos orgânicos vivos durante sua ausência. [...] Para os seres fungóides alados, carregar os cilindros cerebrais através do espaço era uma tarefa simples. (LOVECRAFT, 2013, p.465-466)

O objeto mediador em Lovecraft torna-se um mecanismo constante de contato entre o real e o cósmico de sua mitologia, um espaço onde a realidade tanto pode reconhecer o evento fantástico e com ele ser capaz de desenhar novos espaços e entendimentos, como também é capaz de deslocar este personagem em direção à incompreensão e à loucura efetivada pelo objeto mediador.

Já em Aladim e a Lâmpada Mágica temos um conto onde o protagonista, Aladim, é representado como um adolescente inconsequente e imaturo, graças à sua negativa em seguir a carreira de seu já falecido pai. Durante um encontro com um feiticeiro local, Aladim descobre a existência de uma lâmpada mágica capaz de invocar um Djin que realizaria qualquer desejo. A partir desta descoberta Aladim parte em direção à lâmpada maravilhosa e com ela entra em contato com o fantástico a partir deste objeto.

A aparição de um mecanismo fantástico não é questionada por Aladim, que, já tendo entrado em contato com o feiticeiro e reconhecido seu poder mágico, tem o Djin como seu companheiro e com ele adquire riquezas e passa de um jovem rebelde para um adulto responsável por um reino.

A passagem do empírico para o fantástico tem em Aladim duas facetas: a primeira é o rompimento do real com o ficcional sem nenhum estranhamento, 0 que é explicado por Todorov quando o autor identifica uma obra como maravilhosa, onde "os elementos sobrenaturais não provocam qualquer reação particular nem nas personagens, nem no leitor implícito. "(TODOROV, 2014, p.59-60). O objeto mediador não está aqui para causar pavor e exclusão, como 
em Lovecraft, mas é reconhecido como algo pertencente àquele mundo, inerente à realidade maravilhosa.

A segunda faceta recai sobre a transformação do jovem inconsequente para o homem responsável a partir do objeto mediador e por escolha do próprio protagonista. É Aladim que pede ao Djin que Ihe conceda riquezas e um palácio para administrar, não mais apenas tempo ocioso e travessuras. Com isso, Aladim e a Lâmpada Mágica torna-se um exemplo de narrativa onde o objeto mediador detém diversos significados além do usual horror e surpresa da passagem do real empírico para o real fantástico.

O descobrimento do Djin não realiza uma mudança na percepção completa do ambiente empírico, mas serve principalmente para uma passagem psicológica e mundana, pessoal, uma alteração completa da percepção do mundo, mas sem um questionamento quanto ao evento fantástico-maravilhoso.

O objeto mediador exerce o poder de questionar a realidade como um mecanismo de mediação tanto física como psicológica. O mesmo não existe unicamente no efeito de assustar ou surpreender o protagonista e o leitor a partir de um rompimento com a realidade, mas sim na maneira como um objeto tornase capaz de rearticular o universo e o horizonte de expectativa do personagem e do leitor implícito.

Eric Rabkin, ao falar sobre a alteração em $180^{\circ}$ da realidade acerca da literatura fantástica, enfatiza este efeito ao comparar a experiência do leitor implícito com a experiência dos personagens, construindo um efeito de dúvida, onde o personagem, ao ignorar a fonte fantástica do objeto mediador, causa no leitor implícito um rompimento das experiências empíricas, questionando assim a validade do conceito do real.

The fantastic is a quality of astonishment that we feel when the ground rules of narrative worlds are suddenly made to turn about $180^{\circ}$. We recognize this reversal in the reactions of characters, the statements of narrators, and the implications of structure, all playing on and against our whole experience as people and readers. (RABKIN, 1977, p.41) ${ }^{2}$

Vale lembrar nesse ponto que o objeto mediador em Aladim não pode ser confundido com o que chamamos de objeto de segundo nível, onde acontece a

2 O fantástico é um tipo de espanto que sentimos quando as regras básicas dos mundos narrativos são subitamente viradas em 180․ Reconhecemos essa inversão nas reações dos personagens, nas afirmações dos narradores e nas implicações da estrutura narrativa, todas jogando contra a nossa experiência como pessoas e leitores. - Tradução Nossa

Revista de Letras JUÇARA, Caxias - Maranhão, v. 02, n. 01, p. 263 - 277, jul. 2018 | 267 
aparição de um ser mágico. O Djin é o reflexo do efeito da lâmpada, ou seja, é o objeto mundano que ocasiona sua aparição, tornando-o foco da análise como mediação, e não o contrário.

Podemos perceber que este primeiro nível de objeto mediador é caracterizado pela imposição de algo inanimado que adentra à realidade a partir de novos vieses de percepção, ganhando espaço na realidade como algo dialogável e influenciador direto das ações realistas. É um nível de interação que prevê a necessidade de uma influência sobre o objeto, uma humanização do inanimado afim de romper a realidade em direção do fantástico.

O segundo nível de aparição do objeto mediador tem a ver com seres fantásticos, mitológicos ou maravilhosos que não são intercedidos por um objeto, mas sim por sua própria força. Os exemplos que escolhemos para exemplificar este evento são Ligéia, de Edgar Alan Poe (2008), e O Defunto, de Eça de Queirós (2004)

O narrador de Ligéia é um homem que contrai matrimônio uma segunda vez afim de preencher sua solidão após a morte de sua primeira esposa, Ligéia. Contudo, sua segunda esposa, Rowena, torna-se odiosa e não suporta sua presença, representando mais um fardo do que uma companhia.

Rowena acaba ficando doente pouco tempo após o casamento, um mal que a levaria à morte, mas não antes que o protagonista começasse a entrar em contato com o inexplicável.

Em uma de suas buscar rápidas afim de amenizar o sofrimento de Rowena com um cálice de vinho, o protagonista sente algo estranho: "Senti que um objeto palpável, embora invisível, tinha roçado por mim e vi, sobre o tapete dourado, bem no meio do intenso clarão lançado pelo incensório, uma sombra uma indefinida e desmaiada sombra de aspecto angélico" (POE, 2008, p.24). Contudo, este sentimento passa despercebido pela quantidade avantajada de ópio que havia consumido recentemente.

Esta deixa do narrador inicia o processo de reconhecimento do fantástico pelo leitor que possua algum repertório das narrativas de Poe. O suspense de algo incongruente com a realidade entra em embate com uma possível alucinação por causa do ópio, e ajuda a construir o pacto ficcional para o contato posterior com o objeto mediador. 
A morte de Rowena acaba com as esperanças desse narrador em permanecer em paz. Olhando para o leito de morte de sua esposa, passando a madrugada entre calafrios e barulhos estranhos, o cadáver se ergue, e temos a apresentação do objeto mediador que repentinamente confirma a presença do fantástico para o leitor:

\begin{abstract}
O cadáver, repito, agitou-se, e dessa vez mais vigorosamente do que antes. As tintas da vida assomaram-lhe à face com energia extraordinária (os braços estavam relaxados) e, salvo pelas pálpebras, fortemente cerradas, e pelas ataduras e vestes mortuárias, que ainda emprestavam um caráter sepulcral a figura, eu poderia pensar que Rowena houvesse rompido desesperadamente as algemas da morte. $\mathrm{E}$ se essa ideia não foi, então, imediatamente aceita, não mais pude recusá-la quando, erguendo-se do leito, cambaleando com passos inseguros, olhos fechados e o jeito de alguém mergulhado num sonho, a coisa antes amortalhada avançou, corporal e palpavelmente, até o meio do aposento. (POE, 2008, p.27)
\end{abstract}

Independente da escolha que façamos entre o empirismo da aparição do fantástico ou da reação alucinógena que o narrador pode estar sofrendo, encontramos neste exemplo uma narrativa que carrega um suspense aparentemente mundano, o medo da solidão e da morte, até que o leitor é atingido com a aparição de algo que desafia seu reconhecimento do real.

O leitor de Poe que possui um repertório de leitura de suas obras pode reconhecer as nuances que a narrativa coloca afim de apresentar o fantástico como a sombra palpável vista pelo narrador - mas, mesmo com a predileção pelo fantástico, a narrativa de Poe consegue empenhar este objeto mediador em uma relação de surpresa. O corpo fantasmagórico, apesar de possuir características físicas quando entra em contato com o protagonista, é o único momento da narrativa no qual o narrador dá atenção para este efeito, sinônimo de uma escolha de pacto com a realidade que agora deixa de ser natural e parte para 0 fantástico.

Já no último parágrafo da narrativa, o narrador nos surpreende mostrando que o objeto mediador é um evento fantástico não só pela surpresa em sua revelação, como também por tratar-se do corpo de Ligéia, e não mais o de Rowena, ocasionando um rompimento também do horizonte de expectativa.

Edgar Alan Poe foi um mestre na arte do suspense e do horror psicológico. A aparição do objeto mediador em suas narrativas torna-se então um imenso cabedal de referências afim de localizarmos estas aparições e, com elas,

Revista de Letras JUÇARA, Caxias - Maranhão, v. 02, n. 01, p. 263 - 277, jul. 2018 | 269 
construirmos uma percepção dos momentos em que o real e o fantástico são transpostos para o leitor modelo.

Em O Defunto, de Eça de Queiroz, é narrada a história de Rui de Cardenas, um devoto de Nossa Senhora do Pilar apaixonado por uma mulher casada, Dona Leonor. O Esposo de Leonor, um abastado fidalgo de nome Alonso de Lara, enciumado ao extremo dos contatos e desejos de Rui por sua esposa, resolve empreender uma armadilha para que o mesmo venha a ser morto pela lâmina de uma adaga.

A narrativa caminha para uma resolução realista, até que o fantástico incorre a partir de um defunto que, após uma longa conversa, se passa por Rui de Cardenas, tomando o golpe de adaga em seu lugar.

Neste texto, o objeto mediador é instaurado na narrativa a partir de uma forma física, influenciando inclusive o destino do protagonista, mas nem por isso deixa de ser caracterizado como um espectro, pois seu corpo já se encontrava morto a algum tempo no Cerro dos Enforcados.

O encontro de Rui com o fantástico é descrito de forma condescendente. O defunto o chama quando ele passava pelo Cerro do Enforcados e o protagonista dialoga com o espectro. Aqui, a passagem do real para o fantástico acontece sob a influência de um desejo não relatado, constrói um lugar de ancoragem para a mistura entre o real e o fantástico e ajuda a localizar os eventos de um reino empírico realista para o reino fantástico.

A aparição do objeto mediador neste caso conduz a uma atmosfera naturalista, um lugar onde a existência humana é apresentada com objetos concretos e diretos. Rui e Leonor não podiam ficar juntos, a não ser que Alonso morresse, mas os personagens não agem diretamente em favor deste evento. É o fantástico que atua neste papel e, em seguida, é a consciência de Alonso que não o deixa viver em paz, fazendo-o definhar por não entender como pode ter matado um homem morto.

Tanto o exemplo da obra de Poe como o de Eça representam a aparição e ação do objeto mediador a partir de algo que não só pode ser visto, como também possui características humanas. Visualmente o personagem e o leitor podem ser enganados durante o processo até que o fantástico se revele. Diferente do objeto de primeiro nível, aqui, o objeto mediador está entre a 
realidade e a ficção, permeando ambos os reinos enquanto os personagens são levados a questionar seu próprio lugar no tempo e no que há além da vida.

David Roas, ao falar sobre a aparição do fantástico na realidade do leitor ajuda a explicar porque a narrativa fantástica, ao revelar uma ação antinatural, passa para um ambiente realista o que deveria ser irreal, fantástico, revertendo o efeito de segurança que o leitor possa ter construído antes da leitura, colocando-o mais uma vez em um lugar inseguro e quebradiço, tornando a realidade ainda mais maleável e questionável.

\begin{abstract}
Assim, para que a história narrada seja considerada fantástica, deve-se criar um espaço similar ao que o leitor habita, um espaço que se verá assaltado pelo fenômeno que transtornará sua estabilidade. É por isso que o sobrenatural vai supor sempre uma ameaça à nossa realidade, que até esse momento acreditávamos governada por leis rigorosas e imutáveis. A narrativa fantástica põe o leitor diante do sobrenatural, mas não como evasão, e sim, muito pelo contrário, para interroga-lo, fazê-lo perder a segurança diante do mundo real. (ROAS, 2014, p.31)
\end{abstract}

O objeto mediador deixa este espaço de insegurança ainda mais eminente, pontua o lugar onde o leitor pode perceber, com certa segurança, que algo fantástico aconteceu ali, que as leis da física não são mais regidas com segurança e que a própria realidade pode ser questionada.

No terceiro tópico, elencamos as aparições do objeto mediador como interseção entre o homem e alguma divindade. O maior exemplo que encontramos da ativação deste objeto encontra-se em narrativas maravilhosoreligiosas, onde a crença de um personagem é recebida por algo sobrenatural e, a partir dela, o fantástico entra no ambiente realista.

Os consagrados livros religiosos, como o Alcorão, a Bíblia, o Tanakh e demais textos considerados sagrados, são exemplos eminentes da presença deste objeto mediador quando, durante estas narrativas, encontramos personagens que conseguiram um milagre, ou um efeito fantástico, a partir de seu desejo e contato com a divindade de sua crença.

Assim como nos tópicos anteriores, trazemos dois exemplos para ajudar a entender o efeito do objeto mediador a partir desta característica. São eles $O$ Cemitério, de Stephen Edwin King, e O Sapateiro e a Força Maligna, de Anthon Tchekhov.

Em O Cemitério temos o jovem médico Louis Creed, sua esposa, dois filhos e um gato que acabaram de se mudar para uma grande casa no estado do 
Maine, nos Estados Unidos. Após encontrar seu vizinho e descobrir segredos obscuros sobre um estranho cemitério indígena nos arredores de sua casa, Louis resolve visitá-lo e enterrar lá o gato da família, que morrera subitamente enquanto o resto da família viajava. Para sua surpresa o gato volta à vida, e a partir dali inicia-se o poderoso encontro de Louis Creed com a possibilidade de trazer qualquer um de volta, tarefa que possuiria um preço muito amargo, fato que o personagem percebe tarde demais.

Em um evento desafortunado, seu filho sofre um acidente gravíssimo e acaba morrendo. Frente a esta situação, Louis Creed resolve interceder por seu filho, roubando seu corpo já enterrado e o levando para o cemitério indígena para que o mesmo voltasse à vida. As intenções de Louis acabam se concretizando, mas não da forma esperada, considerando que o ser que ressuscitara não fora seu filho, mas sim algo demoníaco e assustador.

Percebe-se que o objeto mediador neste caso não possui uma forma ou uma descrição. Ele advém diretamente do lugar e do desejo de reversão da morte. É descrito que aquele lugar onde o cemitério se encontra é amaldiçoado, que nada de bom pode retornar daquelas profundezas, mas, no pavor e na insensatez do momento, Louis Creed não se importa e reza para alguma entidade que não conhece afim de trazer seu filho de volta.

O objeto mediador não existe senão em quem intercede. A maldição do cemitério serve unicamente como zona de controle. Acreditar na possibilidade de ressurreição é o que faz Louis Creed trazer seu gato de volta à vida, e logo após seu filho, mesmo sabendo que seu gato voltara diferente.

Stephen King trabalha muito com medos humanos, suas narrativas continuamente utilizam do fantástico para dialogar com um mal que atinge o leitor no universo empírico. O objeto mediador existe também na vida real neste caso. Recebendo ou não uma interseção, a crença é eminente na vida das pessoas de forma geral. $O$ desejo de que algo rompa a realidade e altere sua vida para um destino melhor é o que dá forças para mantê-los em pé. Por isso, consideramos este tipo de objeto mediador o mais poderoso em provocar a catarse, por possibilitar, dentro do ambiente fantástico e a partir de eventos sobrenaturais, relativizar a realidade com a obra ficcional e, com isso, retirar o leitor de sua zona de conforto. 
Camarani (2014), ao falar da crítica de Roas sobre certos hibridismos do fantástico puro com o fantástico religioso, ajuda a dar ênfase a característica do parágrafo acima, pois confirma que o efeito religioso, a solicitação fantástica, o desejo pelo milagre ajuda a criar um espaço dialógico entre a narrativa fantástica e o leitor, principalmente graças a influência que o efeito religioso pode possuir.

\begin{abstract}
Como aponta Roas sobre esse tipo de narrativa, não se trata de persuadir o leitor da verdade dos eventos, mas de construir um relato coerente que permita desfrutar do prazer estético do sobrenatural, de uma posição distanciada e segura a respeito da possibilidade efetiva do que foi narrado. Assim, a enunciação distanciada do relato, o espaço rural, o afastamento temporal dos fatos e sua explicação religiosa impedem que o leitor ponha em contato os acontecimentos do texto com sua concepção de mundo. (CAMARANI, 2014, p.171, grifo nosso)
\end{abstract}

Em O Sapateiro e a Força Maligna, de Anthon Tchekhov, temos a exaltação e participação de um ser fantástico visando à alteração da realidade a partir da interseção e do pedido do protagonista para que lhe fosse proporcionado tudo o que desejava na vida.

No conto, acompanhamos a história do sapateiro Fiódor Nilov, um homem pobre e ressentido com a vida. Fiódor não aceitava que outros tivessem muito dinheiro e tempo de sobra e ele pouco dinheiro e nenhum tempo para aproveitar a vida, continuamente reclamando da fortuna dos homens ricos, enquanto praguejava sobre a própria sorte.

Em um encontro desafortunado, Fiódor descobre que um de seus clientes, o senhor de óculos azuis, é o próprio diabo, e com isso decide vender sua alma afim de ser rico. $O$ diabo aceita seu pedido e the concede uma vida de luxo, uma esposa linda e muito tempo livre, porém, Fiódor não consegue aproveitar sua nova realidade, pois percebe que outros problemas assomam os ricos - obrigações e proibições que ele não possuía antes, em sua vida simples e desapercebida de sapateiro.

A narrativa leva Fiódor a aceitar sua posição como pobre e viver a vida tranquilamente, sabendo que todos possuem seus sofrimentos, enquanto nada vale o suficiente para que entregue sua alma para a eternidade de sofrimento.

A presença do fantástico acontece na interferência do demônio solicitada por Fiódor. Suas suspeitas prévias a respeito do homem de óculos azuis são pequenos indícios do fantástico religioso e popular que só se realiza graças ao 
pedido do próprio protagonista, quando, ao observar que o homem possuía patas de cavalo no lugar dos pés entra em exaltação:

Em primeiro lugar, deveria fazer o sinal-da-cruz, depois deixar tudo e
correr para baixo. No mesmo instante, porém, refletiu que era a primeira
vez, e provavelmente a última, que encontrava a força maligna e que
seria estúpido deixar de aproveitar seus serviços. Dominou-se, por
conseguinte, e resolveu tentar a sorte. Colocando as mãos atrás, para
não se persignar, tossiu respeitosamente e começou: - Dizem que não
há coisa pior, nem mais repugnante no mundo que a força maligna, mas
eu penso. Vossa Alta Nobreza, que a força maligna é a mais instruída. O
diabo, perdoe-me, tem pata de cavalo e rabo, mas, em compensação, é
mais inteligente que muito estudante. (TCHEKHOV in COSTA, 2006,
p.313)

O fantástico só acontece graças ao chamado por ele. Aqui, o objeto mediador é o poder da palavra e da crença, que só existe graças aos inflamados desejos que podem alcançar espaços que rompem o horizonte empírico e adentram nos reinos do fantástico para serem realizados.

A oração é o ponto de intersecção entre realidade empírica e fantástico. $O$ ser fantástico não é questionado e, imediatamente após a aparição de uma imagem que faz referência ao demoníaco (a pata de cavalo no lugar dos pés), ele é aceito e imbuído do poder de realizar o sobrenatural.

O objeto mediador é tratado como uma ação proveniente de um desejo. A conexão acontece a partir da crença com a realização, do real com o sobrenatural, que dialogam afim de permitir que o fantástico aconteça. Logo, o objeto mediador pode ser visto como o centro da ação que prova a existência do fantástico na narrativa, sem o qual seríamos apresentados ao fantástico de forma abrupta, possivelmente encontrando dificuldade em construir o pacto ficcional e com diminuição do efeito catártico.

Este terceiro modelo de objeto mediador apresenta um horizonte de expectativa que se assemelha às relações pessoais de uma parcela considerável dos leitores. Acreditar em uma divindade onipotente e onipresente é recorrente e facilmente identificável, bastando que percebamos a quantidade imensa de religiões e crenças que nascem e se expandem pelo mundo diariamente.

O leitor modelo que entra em contato com o fantástico a partir deste mecanismo pode construir o pacto ficcional de forma mais fluente, considerando suas correlações e compreendendo que a obra literária que empenha esforços em romper os horizontes empiristas é também um lugar onde o leitor pode refletir 
sobre a realidade, e com ela ser capaz de validar outros mundos a partir do fantástico.

Como Roas comenta, "a narrativa fantástica nos situa inicialmente dentro dos limites do mundo que conhecemos, [...] para logo rompê-lo com um fenômeno que altera a maneira natural e habitual como as coisas ocorrem nesse espaço cotidiano" (2014, p.138), assim o objeto mediador torna-se parte indissolúvel deste processo, permitindo que ambos os universos se unam e assim consigam obter o efeito fantástico.

\section{CONCLUSÃO}

Este trabalho teve como exercício principal identificar três formas de apresentação do objeto mediador em obras com temáticas fantásticas.

Foi possível perceber que estas aparições reconhecem na construção da narrativa fantástica um lugar capaz de construir um elo entre realidade e ficção, e com ela remover o leitor modelo de sua zona de segurança, transpondo-o para o universo fantástico a partir de uma ferramenta narrativa.

Realizou-se também uma apresentação do emprego do objeto mediador em algumas obras, construindo um processo de observação e percepção dele como movimento da narrativa em direção ao fantástico, articulando tanto os personagens que descobrem estar fora do que antes era real empírico para eles, como para o leitor que, após o pacto ficcional ser estabelecido, é capaz de reconhecer a fragilidade com que a realidade pode ser rompida na obra literária.

Por fim, o exercício de elencar três possíveis modos de aparição do objeto mediador serviu para notarmos como o autor da obra fantástica é capaz de, a qualquer momento, distorcer a realidade e, mesmo assim, manter o leitor preso à leitura, sem retirá-lo de seu lugar como leitor modelo, ampliando assim seu horizonte de expectativa referente a narrativas que se utilizam desta categoria para contar suas histórias.

Acredita-se que a presença e a utilização do objeto mediador façam-se notar na maior parte das narrativas fantásticas, seja por umas destas três categorias que levantamos ou por qualquer outra que não conseguimos englobar nelas. O que este trabalho nos deixa é o sentimento de segurança de que o real e o fantástico não são lugares separados. Quando o fantástico ocorre, ambos 
coexistem no mesmo plano, ainda que um não consiga visualizar o outro até que um entremeio surja.

A literatura fantástica é, para demais efeitos e em conluio com as mediações deste trabalho, um constante exercício de ressignificação da realidade baseada no que nunca vimos ou sentimos, mas que, a qualquer instante, pode ser destituído de seu valor de verdade e, com isso, demonstrar uma nova realidade. Como aponta Roas: "A literatura fantástica nos revela a falta de validade absoluta do racional e apossibilidade da existência [...] de uma realidade diferente e incompreensível." (ROAS, 2014, p.32)

\section{THE MEDIATOR OBJECT IN FANTASTIC LITERATURE}

ABSTRACT: This work aims to study the appearance and effect of the mediator object in the fantastic narrative, as well as to categorize three possible ways of using this tool in the narrative. From the proposal of Ceserani on the mediator object, where the critic classifies it as the record of an unequivocal truth because inexplicable and unbelievable within the narrative, the article seeks to evidence these apparitions in the works as a mechanism of connection between reality and fiction. The three ways of listing the form of appearance of this mechanism (the inanimate physical object, the supernatural physical entity and the invocation of an unseen supernatural being) are studied based on examples, punctuating their presences and their influences in the narrative plot. Therefore, it is proposed to study a narrative mechanism that evidences the presence of the supernatural and places the fantastic narrative beyond doubt. The appearance of the mediating object will generally be connected with the unquestionable presence of the supernatural, so it becomes powerful as a tool and so important on its activity of mediation between real and fantastic.

KEYWORDS: Mediator Object; Fantastic; Supernatural

\section{REFERÊNCIAS}

BESSIÈRE, Irène. O relato fantástico: forma mista do caso e da adivinha. FronteiraZ, São Paulo, v. 3, n. 03, set/2009. Disponível em: $<$ http://www4.pucsp.br/revistafronteiraz/numeros_anteriores/n3/download/pdf/revis ta_fronteiraz_impressa03.pdf >. Acesso em: Jull2018.

CAILLOIS, Roger. Images, images. Paris : Corti, 1966.

CAMARANI, A. L. S. A Literatura Fantástica: Caminhos teóricos. São Paulo, Editora Cultura Acadêmica, 2014.

CESERANI, Remo. O Fantástico. Trad. Nilton Cezar Tridapalli. Curitiba, Ed.UFPR, 2006.

LOVECRAFT, H. P. Os melhores contos de H. P. Lovecraft. Trad. Guilherme da Silva Braga. São Paulo. Hadra. 2013. 
POE, E.A. Histórias Extraordinárias. Trad. José Paulo Paes. São Paulo. Companhia das Letras, 2008.

QUEIROZ, E. Contos. São Paulo. Martins Claret, 2004.

RABKIN, E. S. The Fantastic in Literature. New Jersey. Princeton University, 1977.

ROAS, David. A Ameaça do Fantástico: Aproximações Teóricas. Trad. Julián Fuks. São Paulo. Editora Unesp, 2014.

TCHEKHOV, A. P. O Sapateiro e a Força Maligna. In: COSTA, F. M. Os Melhores Contos Fantásticos, Trad. Adriana Lisboa. Rio de Janeiro. Nova Fronteira, 2006.

TODOROV, Tzetan. Introdução a Literatura Fantástica. Trad. Maria Clara Correa Castello. São Paulo. Editora Perspectiva, 2014.

Data da Submissão: 28/04/2018

Data da Aprovação: 24/07/2018 